\title{
Susceptibility of Mycobacterium tuberculosis to first-line antimycobacterial agents in a Brazilian hospital: assessing the utility of the tetrazolium (MTT) microplate assay
}

\author{
Michela De Luca Ferrari', Maria Alice da Silva Telles ${ }^{4}$, Lucilaine Ferrazolii ${ }^{4}$, Carlos Emílio Levy ${ }^{3}$, \\ Maria Cecília Barison Villares ${ }^{3}$, Maria Luiza Moretti ${ }^{1,2}$, Mariângela Ribeiro Resende ${ }^{1,2}{ }^{+}$ \\ ${ }^{1}$ Disciplina de Doenças Infecciosas, Departamento de Clínica Médica ${ }^{2}$ Seção de Epidemiologia Hospitalar, Hospital de Clínicas \\ ${ }^{3}$ Departamento de Patologia Clínica, Faculdade de Ciências Médicas, Universidade Estadual de Campinas, Campinas, SP, Brasil \\ ${ }^{4}$ Instituto Adolfo Lutz, Secretaria de Saúde do Estado de São Paulo, São Paulo, SP, Brasil
}

We conducted a cross-sectional, hospital-based study between January 2006-March 2008 to estimate the resistance of Mycobacterium tuberculosis to first-line drugs in patients with tuberculosis at a Brazilian hospital. We evaluated the performance of the [3-(4,5-dimethylthiazol-2-yl)-2,5-diphenyl-tetrazolium bromide] (MTT) microplate assay compared with the Bactec-MGIT $960^{\mathrm{TM}}$ system for mycobacteria testing. The prevalence of resistance in $\mathrm{M}$. tuberculosis was $6.7 \%$. Multidrug-resistance [resistance to rifampicin (RMP) and isoniazid (INH)], INH-resistance and streptomycin (SM)-resistance accounted for $1 \%, 3.8 \%$ and $3.8 \%$ of all resistance, respectively, and all isolates were susceptible to ethambutol (EM). The resistance was primary in four cases and acquired in three cases and previous treatment was associated with resistance $(p=0.0129)$. Among the $119 \mathrm{M}$. tuberculosis isolates, complete concordance of the results for INH and EM was observed between the MTT microplate and Bactec-MGIT $960^{\mathrm{TM}}$ methods. The observed agreement for RMP was 99\% (sensitivity: 90\%) and 95.8\% for SM (sensitivity 90.9\%), lower than those for other drugs. The MTT colourimetric method is an accurate, simple and low-cost alternative in settings with limited resources.

Key words: tuberculosis - resistance - drug susceptibility test - tetrazolium - colourimetric method - hospital

Mycobacterium tuberculosis multidrug resistance (MDR) is an emerging global problem. The World Health Organization has estimated that $14 \%$ of all new tuberculosis (TB) cases involve MDR (WHO 2008). In the last decade, MDR-TB was observed in $0.9 \%$ of new Brazilian cases diagnosed in primary health care units (Natal et al. 1997). However, according to the Brazilian Ministry of Health Program, this epidemiological trend is changing: recent data indicate increased resistance and the initial standard treatment regimen now includes four drugs (MS/SVS 2009).

Early detection of $M$. tuberculosis resistance is a concern at local and international levels, especially for health care facilities in metropolitan areas with high population densities, high human immunodeficiency virus (HIV) infection rates and large numbers of institutionalized and homeless people. New drug susceptibility tests (DST) must be developed and implemented that are accurate enough to identify drug resistance, but that are also low-cost, sustainable and accessible. Many DSTs have attempted to meet these requirements and colorimetric assays have been proposed as cost-effec-

+ Corresponding author: mresende@hc.unicamp.br

Received 6 November 2009

Accepted 26 May 2010 tive alternatives to high-cost, automated phenotyping and genotyping methods. Colorimetric methods using alamarBlue, resazurin or 3-(4,5-dimethylthiazol2-yl)-2,5-diphenyl-tetrazolium bromide (MTT) reveal cellular viability in the presence of variable drug concentrations and allow the determination of the drugs' minimum inhibitory concentration (MIC) (Franzblau et al. 1998, Palomino \& Portaels 1999, Caviedes et al. 2002, Ribeiro et al. 2004).

In this study, we tested TB patients at a Brazilian hospital to estimate the prevalence of resistance of $M$. tuberculosis to first-line drugs and to evaluate the performance of the MTT microplate assay compared with Bactec-MGIT 960'

\section{PATIENTS, MATERIALS AND METHODS}

A retrospective, cross-sectional study was performed at a Brazilian tertiary health-care facility in the Campinas metropolitan area, a region with a population of five million and a recent TB incidence rate of 48 per 100,000 inhabitants. We defined two study groups: the prevalence study group (P-group) and the MTT performance evaluation group (MTT-group). The P-group included patients of at least 14 years of age with a positive $M$. tuberculosis culture diagnosis reported to the surveillance system between January 2006-March 2008. To select the P-group, we evaluated 360 cases that were reported to the surveillance system and included 105 patients. The MTT-group was composed of all of the patients in the P-group and an additional 14 cases with confirmed resistance to first-line drugs prior to the study. 
The drug susceptibility patterns of M. tuberculosis were tested using the MTT assay and Bactec-MGIT $960^{\mathrm{TM}}$. Reference susceptibility patterns were obtained from Bactec-MGIT 960 ${ }^{\mathrm{TM}}$ performed by Mycobacteriology Division of the Adolfo Lutz Institute, the regional laboratory of the state of São Paulo (SP). The MTT assay was performed at the Mycobacteriology Laboratory, Division of Clinical Pathology, State University of Campinas (UNICAMP) according to Franzblau et al. (1998) for the following drugs: isoniazid (INH), rifampicin (RMP), ethambutol (EM) and streptomycin (SM). M. tuberculosis suspensions were prepared by inoculating colonies from slants into $2 \mathrm{~mL}$ of $7 \mathrm{H} 9$ broth (Sigma Chemical Co, St. Louis, MO, USA) and incubating at $37^{\circ} \mathrm{C}$ for seven days. The turbidity was adjusted to McFarland Standard 3 by adding Middlebrook $7 \mathrm{H} 9$. Middlebrook $7 \mathrm{H} 9$ was prepared with $0.47 \mathrm{~g}$ of $7 \mathrm{H} 9$ broth base (Difco, Detroit, MI, USA), $0.2 \mathrm{~mL}$ of glycerol, $90 \mathrm{~mL}$ of distilled water and $10 \mathrm{~mL}$ of a mixture of oleic acid, albumin, dextrose and catalase (OADC) (Becton-Dickinson). RMP and INH stock solutions $(10 \mathrm{mg} / \mathrm{mL})$ were prepared in methanol and water, respectively. EM stock solutions were prepared in distilled water with and without $20 \%$ ethanol and SM solutions were prepared in distilled water with and without $5 \%$ phenol.

Microdilution plates were prepared by adding $200 \mu \mathrm{L}$ of sterile water to all outer wells and $100 \mu \mathrm{L}$ of $7 \mathrm{H} 9$ broth to columns $2-11$ in rows B-G. Then, $100 \mu \mathrm{L}$ of 4X antibiotic solutions (INH, RMP, SM or EM) were added to rows B-G of column 2. To perform the dilution, $100 \mu \mathrm{L}$ were transferred from row B-G of column 2 to column 3 with a multi-channel pipette. The antibiotics were serially diluted 1:2 in this manner except in column 11 , where the $100 \mu \mathrm{L}$ of excess media was discarded. The final drug concentration ranges were $0.015-16 \mu \mathrm{g} / \mathrm{mL}$ for INH, $0.015-16 \mu \mathrm{g} / \mathrm{mL}$ for RMP, $0.01-16 \mu \mathrm{g} / \mathrm{mL}$ for SM and $0.03-16 \mu \mathrm{g} / \mathrm{mL}$ for EM. At this point, $100 \mu \mathrm{L}$ of a log-phase M. tuberculosis bacterial suspension (2030 days old) were added to rows B-G in columns 2-11. Bacteria were not added to row $\mathrm{H}$ of columns 10 and 11 and these wells served as inoculum controls. The plates were sealed with parafilm in plastic bags and incubated at $37^{\circ} \mathrm{C}$ for six or seven days. On day six, $15 \mu \mathrm{L}$ of $5 \mathrm{mg} / \mathrm{mL}$ MTT (Sigma-Aldrich) in a 1:9 ratio of ethanol:water was added to well $\mathrm{H} 10$. The plate was incubated at $37^{\circ} \mathrm{C}$ for $24 \mathrm{~h}$ and, if the color of H10 turned purple, MTT was added to all wells and the color was recorded at $24 \mathrm{~h}$. If the color of well H10 remained yellow, the plates were incubated for another $24 \mathrm{~h}$. At this point, MTT solution was added to well H11 and the plate was incubated for another $24 \mathrm{~h}$ to observe the color change. Isolates were considered to be drug susceptible if their MICs were below or equal to the critical concentrations reported by Martin et al. (2005): INH, $0.25 \mu \mathrm{g} / \mathrm{mL}$; RMP, $0.5 \mu \mathrm{g} / \mathrm{mL}$; $\mathrm{EM}, 4 \mu \mathrm{g} / \mathrm{mL}$; SM, $1 \mu \mathrm{g} / \mathrm{mL}$. The critical concentrations of Bactec-MGIT $960^{\mathrm{TM}}$ reported by the manufacturer's protocol were as follows: INH, $0.10 \mu \mathrm{g} / \mathrm{mL}$; RMP, $1.0 \mu \mathrm{g} / \mathrm{mL} ; \mathrm{EM}, 5.0 \mu \mathrm{g} / \mathrm{mL} ; \mathrm{SM}, 1.0 \mu \mathrm{g} / \mathrm{mL}$.

Statistical analysis was performed with Epi-Info version 6.04b (Centers for Disease Control and Prevention, Atlanta, GA, USA). Categorical variables were analyzed with Chi-square (Yates' correction) and two-tailed Fisher's exact tests. P values of $<0.05$ were considered statistically significant. The study was approved by the Ethical Committee of the Faculty of Medical Sciences of UNICAMP.

\section{RESULTS}

Among the 105 P-group patients, 78 (74.3\%) were male and the median age was 36 years. Pulmonary presentation alone was observed in $68(64.8 \%)$ cases, extra-pulmonary in $11(10.5 \%)$ cases and combined (pulmonary and extra-pulmonary) in $26(24.7 \%)$ patients. Disseminated disease occurred in seven $(18.9 \%)$ cases. Thoracic X-rays were suggestive of TB in $82(78.1 \%)$ cases. Among the $94(89.5 \%)$ patients with pulmonary involvement, $66(62.9 \%)$ had sputum positive for acidfast bacilli and $82(78.1 \%)$ had M. tuberculosis-positive sputum cultures. In other specimens, acid-fast bacilli were observed in $13(12.4 \%)$ cases and the culture was positive in $39(37.1 \%)$ cases. HIV co-infection was diagnosed in $39(37.1 \%)$ cases. Of the 10 patients that had previous treatment, six $(5.7 \%)$ were cured, three $(2.8 \%)$ were in default of treatment and one case failed.

The prevalence of drug-resistant $M$. tuberculosis was $6.7 \%$, MDR was detected in a single case and resistance to INH and SM was detected in $3.8 \%$ of cases (Table I). The resistance was primary in four cases and acquired in three. Previous treatment was associated with resistance $(p=0.0129)$; however, HIV was not related to resistance. Favorable treatment outcomes occurred in 67 (63.8\%) cases, death in $26(24.8 \%)$ cases and default of treatment in $12(11.4 \%)$ cases. Of the seven patients with drug-resistance, four were cured, two died and follow-up data was not available for one. The patient with MDR-TB was cured at the 18th month of the treatment.

Analysis of the MTT-group (119 M. tuberculosis isolates) showed agreement between the MTT and BactecMGIT $960^{\mathrm{TM}}$ methods in $100 \%$ of cases for INH and EM, 99\% for RMP and $95.8 \%$ for SM (Table II). Final results (resistant or susceptible) were similar when ethanol or phenol was added to solubilise EM or SM, respectively.

\section{TABLE I}

Prevalence of resistance to first-line antimycobacterial agents among tuberculosis cases in prevalence study group performed by MTT microplate assay and Bactec-MGIT $960^{\mathrm{TM} a}$

\begin{tabular}{lcccc}
\hline \multirow{2}{*}{ Drug } & \multicolumn{2}{c}{ Resistant } & \multicolumn{2}{c}{ Susceptible } \\
\cline { 2 - 5 } & $\mathrm{n}=7$ & $\%$ & $\mathrm{n}=98$ & $\%$ \\
\hline Isoniazid & 4 & 3.8 & 101 & 96.2 \\
Rifampicin & 1 & 1 & 104 & 99 \\
Ethambutol & 0 & 0 & 105 & 100 \\
Streptomycin & 4 & 3.8 & 101 & 96.2 \\
Isoniazid + rifampicin & 1 & 1 & 104 & 99 \\
\hline Total & 7 & 6.7 & 98 & 93.3 \\
\hline
\end{tabular}

$a$ : the benchmark test when the results were discrepant; MTT: 3-(4,5-dimethylthiazol-2-yl)-2,5-diphenyl-tetrazolium bromide assay. 


\section{TABLE II}

Performance of MTT microplate assay compared with Bactec-MGIT 960 ${ }^{\mathrm{TM}}$ among tuberculosis cases in MTT-group

\begin{tabular}{|c|c|c|c|c|}
\hline \multirow[b]{3}{*}{ Drug } & \multicolumn{3}{|c|}{ MTT } & \multirow{2}{*}{ Agreement } \\
\hline & Bactec-MGIT & Susceptible & Resistant & \\
\hline & $960^{\mathrm{TM}}$ & $\mathrm{n}$ & $\mathrm{n}$ & $\%$ \\
\hline \multirow[t]{2}{*}{ Isoniazid } & $\mathrm{S}$ & 104 & 0 & 100 \\
\hline & $\mathrm{R}$ & 0 & 15 & \\
\hline \multirow[t]{2}{*}{ Rifampicin } & $\mathrm{S}$ & 109 & 0 & 99.1 \\
\hline & $\mathrm{R}$ & 1 & 9 & \\
\hline \multirow[t]{2}{*}{ Ethambutol } & $\mathrm{S}$ & 117 & 0 & 100 \\
\hline & $\mathrm{R}$ & 0 & 2 & \\
\hline \multirow[t]{2}{*}{ Streptomycin } & $\mathrm{S}$ & 108 & 4 & 95.8 \\
\hline & $\mathrm{R}$ & 1 & 6 & \\
\hline
\end{tabular}

MTT: 3-(4,5-dimethylthiazol-2-yl)-2,5-diphenyl-tetrazolium bromide assay.

\section{DISCUSSION}

In our study, the presence of resistant-TB was lower than in other Brazilian studies performed at tertiary care facilities. Although few Brazilian hospital-based studies have specifically evaluated resistance, the resistance rates reported by other studies were higher. For RMP, INH or any drug, the resistance rates varied from 3.6$4.3 \%, 10.9-13 \%$ and $13.3-19.2 \%$, respectively (Brito et al. 2004, de Souza et al. 2006, Aguiar et al. 2009). Our results can be explained by the characteristics of our study population, such as the number of cases evaluated, the absence of previous treatment in the majority of patients and the TB incidence rate in the Campinas metropolitan area being lower than in Rio de Janeiro, where most Brazilian studies have been conducted.

MDR-TB has been evaluated in other Brazilian hospitals at higher rates than observed in the general population. In the 1990s, a national surveillance of resistance in basic health care units reported that $0.9 \%$ of cases were MDR-TB and $8.6 \%$ of all cases were resistant to some drug. Similar results were observed in SP (PablosMéndez et al. 1998, Telles et al. 2005).

An association between resistance and previous treatment was found in our study, as well as in other studies (Fandinho et al. 1999, de Melo et al. 2003, Aguiar et al. 2009). In Brazil, acquired resistance was related to inadequate adherence to treatment, supporting the movement to extend directly observed therapy.

The general performance of the MTT microplate assay was adequate to detect resistance to INH, RMP and $\mathrm{EM}$. The assay results were in agreement with BactecMGIT $960^{\mathrm{TM}}$, but few TB resistance isolates were tested. These results are compatible with results reported by others (WHO 1997, Palomino \& Portaels 1999, Caviedes et al. 2002, Ribeiro et al. 2004, Mengatto et al. 2006). DST for EM and SM has been reported to have low reproducibility (WHO 1997). In a multicentric study of the
MTT assay, Martin et al. (2005) reported specificity and sensitivity for SM of $85 \%$ and $90.5 \%$, respectively. These results are probably associated with the drug's stability. In our study, we added ethanol in small concentrations to improve the stability of EM in the stock solutions and phenol was added for SM solubility. This approach possibly improves the evaluation of EM and SM resistance through MTT evaluation.

In addition, the MTT microplate assay has been widely used to test second-line antimycobacterial drugs. Expertise with this method assumes great importance in the context of the global rise in MDR, primarily in developing countries.

Reported overall efficiencies of the MTT and resazurin assays have been similar with high accuracy, except for SM (Martin et al. 2005, Montoro et al. 2005). According to previous studies, MTT allows for a better interpretation of colors, which facilitates its standardization (Ribeiro et al. 2004). One test for resistance to four drugs using MTT or resazurin costs $\$ 5$ (US) or $\$ 3$ (US), respectively, whereas the test performed by Bactec-MGIT $960^{\mathrm{TM}}$ costs $\$ 39$ (US) (Mengatto et al. 2006, WHO 2008). The use of colorimetric methods to detect drug resistance in $M$. tuberculosis has recently been endorsed by the Strategic and Technical Advisory Group for Tuberculosis (WHO 2009).

The next steps to take towards standardizing the MTT and resazurin colorimetric tests for clinical evaluation depend on phases III (performance) and phase IV (costeffectiveness) clinical trials and involve comparisons with reference methods (Palomino et al. 2007). A study analyzing the cost-effectiveness of five DST methods, including the MTT assay, was performed in Peru and they found that all of the methods to identify MDR-TB in middleincome countries were cost-effective. Including the cost savings from reduced TB transmission, the MTT assay had the second-lowest gained cost per disability-adjusted life-year (\$95 US) (Acuna-Villaorduna et al. 2008). New colorimetric methods now enable the direct diagnosis of resistance in clinical specimens (Pai et al. 2006).

The MTT colorimetric method is an accurate, simple test that costs less than the automated phenotyping and genotyping methodologies. Colorimetric tests are a boon for settings with limited resources and make possible sustainable resistance surveillance, a critical step in global TB control.

\section{REFERENCES}

Acuna-Villaorduna C, Vassall A, Henostroza G, Seas C, Guerra H, Vasquez L, Morcillo N, Saravia J, O'Brien R, Perkins MD, Cunningham J, Llanos-Zavalaga L, Gotuzzo E 2008. Cost-effectiveness analysis of introduction of rapid, alternative methods to identify multidrug-resistant tuberculosis in middle-income countries. Clin Infect Dis 47: 487-495.

Aguiar F, Vieira MA, Staviack A, Buarque C, Marsico A, Fonseca L, Chaisson R, Kristski A, Werneck G, Mello F 2009. Prevalence of anti-tuberculosis drug resistance in an HIV/AIDS reference hospital in Rio de Janeiro, Brazil. Int J Tuberc Lung Dis 13: 54-61.

Brito RC, Gounder C, Lima DB, Siqueira H, Cavalcanti HR, Pereira MM, Kritski AL 2004. Resistência aos medicamentos anti-tuberculose de cepas de Mycobacterium tuberculosis isoladas de pacientes atendidos em hospital geral de referência para tratamento de AIDS no Rio de Janeiro. J Bras Pneumol 30: 335-342. 
Caviedes L, Delgado J, Gilman RH 2002. Tetrazolium microplate assay as a rapid and inexpensive colorimetric method for determination of antibiotic susceptibility of Mycobacterium tuberculosis. J Clin Microbiol 40: 1873-1874.

de Melo FA, Afiune JB, Ide Neto J, de Almeida EA, Spada DT, Antelmo AN, Cruz ML 2003. Aspectos epidemiológicos da tuberculose multirresistente em um serviço de referência na cidade de São Paulo. Rev Soc Bras Med Trop 36: 27-34.

de Souza MB, Antunes CM, Garcia GF 2006. Multidrug-resistant Mycobacterium tuberculosis at a referral center for infectious diseases in the state of Minas Gerais, Brazil: sensitivity profile and related risk factors. J Bras Pneumol 32: 430-437.

Fandinho FCO, Kritski AL, Hofer C, Conde Jr H, Ferreira RMC, Silva MG, Fonseca LS 1999. Drug resistance patterns among hospitalized tuberculous patients in Rio de Janeiro, Brazil, 1993-1994. Mem Inst Oswaldo Cruz 94: 543-547.

Franzblau SG, Witzig RS, McLaughlin JC, Torres P, Madico G, Hernandez A, Degnan MT, Cook MB, Quenzer VK, Ferguson RM, Gilman RH 1998. Rapid, low-technology MIC determination with clinical Mycobacterium tuberculosis isolates by using the microplate Alamar Blue assay. J Clin Microbiol 36: 362-366.

Martin A, Morcillo N, Lemus D, Montoro E, Telles MA, Simboli N, Pontino M, Porras T, León C, Velasco M, Chacon L, Barrera L, Ritacco V, Portaels F, Palomino JC 2005. Multicenter study of MTT and resazurin assays for testing susceptibility to first-line anti-tuberculosis drugs. Int J Tuberc Lung Dis 9: 901-906.

Mengatto L, Chiani Y, Imaz MS 2006. Evaluation of rapid alternative methods for drug susceptibility testing in clinical isolates of $\mathrm{Myco}$ bacterium tuberculosis. Mem Inst Oswaldo Cruz 101: 535-542.

Montoro E, Lemus D, Echemendia M, Martin A, Portaels F, Palomino JC 2005. Comparative evaluation of the nitrate reduction assay, the MTT test and the rezasurin microtitre assay for drug susceptibility testing of clinical isolates of Mycobacterium tuberculosis. J Antimicrob Chemother 55: 500-505.

MS/SVS - Ministério da Saúde do Brasil/Secretaria de Vigilância em Saúde/Departamento de Vigilância Epidemiológica 2009. Programa Nacional de Controle da Tuberculose. Nota técnica sobre as mudanças no tratamento da tuberculose no Brasil para adultos e adolescentes. Available from: portal.saude.gov.br/portal/arquivos/pdf/nota_tecnica_versao_28_de_agosto_v_5.pdf.
Natal S, Toledo A, Penna MLF, Barreto AMW, Vasconcellos G, Gerhardt G 1997. Primary and secondary drug resistance in pulmonary tuberculosis. Int J Tuberc Lung Dis 1 (Suppl. 5): S45.

Pablos-Méndez A, Raviglione MC, Laszlo A, Binkin N, Rieder HL, Bustreo F, Cohn DL, Lambregts-van Weezenbeek CS, Kim SJ, Chaulet P, Nunn P 1998. Global surveillance for antituberculosis-drug resistance, 1994-1997. World Health Organization-International Union against Tuberculosis and Lung Disease Working Group on Anti-Tuberculosis Drug Resistance Surveillance. N Engl J Med 338: 1641-1649.

Pai M, Kalantri S, Dheda K 2006. New tools and emerging technologies for the diagnosis of tuberculosis: part II. Active tuberculosis and drug resistance. Expert Rev Mol Diagn 6: 423-432.

Palomino JC, Martin A, Portaels F 2007. Rapid drug resistance detection in Mycobacterium tuberculosis: a review of colourimetric methods. Clin Microbiol Infect 13: 754-762.

Palomino JC, Portaels F 1999. Simple procedure for drug susceptibility testing of Mycobacterium tuberculosis using a commercial colorimetric assay. Eur J Clin Microbiol Infect Dis 18: 380-383.

Ribeiro MO, Gomes MS, Senna SG, Rossetti MLR, Fonseca LS 2004. Evaluation of rapid microplate assays using cellular-viability indicators to determine patterns of susceptibility to isoniazid and rifampin in Mycobacterium tuberculosis strains. J Bras Pneumol 30: $365-370$.

Telles MA, Ferrazoli L, Waldman EA, Giampaglia CM, Martins MC, Ueki SY, Chimara E, Silva CA, Cruz V, Waldman CC, Heyn I, Hirono IU, Riley LW 2005. A population-based study of drug resistance and transmission of tuberculosis in an urban community. Int J Tuberc Lung Dis 9: 970-976.

WHO - World Health Organization 1997. Anti-tuberculosis drug resistance in the world: The WHO/IUATLD Global Project on Antituberculosis Drug Resistance Surveillance, 1994-1997, WHO, Geneva, 229 pp.

WHO - World Health Organization 2008. Anti-tuberculosis drug resistance in the world: The WHO/IUATLD Global Project on Antituberculosis Drug Resistance Surveillance, 2002-2007, WHO, Geneva, $142 \mathrm{pp}$.

WHO - World Health Organization 2009. Strategic and technical advisory group for tuberculosis (STAG TB). Report of the Ninth Meeting, WHO, Geneva, 41 pp. 